The Journal of Laryngology \& Otology

http://journals.cambridge.org/JLO

Additional services for The Journal of Laryngology \& Otology:

Email alerts: $\underline{\text { Click here }}$

Subscriptions: $\underline{\text { Click here }}$

Commercial reprints: Click here

Terms of use : $\underline{\text { Click here }}$

\title{
Vestibular schwannoma: role of conservative management
}

R Suryanarayanan, R T Ramsden, S R Saeed, R Aggarwal, A T King, S A Rutherford, D G Evans and J E Gillespie

The Journal of Laryngology \& Otology / Volume 124 / Issue 03 / March 2010, pp 251 - 257

DOI: 10.1017/S0022215109992362, Published online: 11 December 2009

Link to this article: http://journals.cambridge.org/abstract_S0022215109992362

How to cite this article:

R Suryanarayanan, R T Ramsden, S R Saeed, R Aggarwal, A T King, S A Rutherford, D G Evans and J E Gillespie (2010). Vestibular schwannoma: role of conservative management. The Journal of Laryngology \& Otology, 124, pp 251-257 doi:10.1017/S0022215109992362

Request Permissions : $\underline{\text { Click here }}$ 


\title{
Vestibular schwannoma: role of conservative management
}

\author{
R Suryanarayanan, R T Ramsden, S R Saeed*, R Aggarwal, A T King $\dagger$, S A Rutherford $\dagger$, \\ D G Evansł, J E GILLESPIE**
}

\begin{abstract}
Objective: To assess the outcome of conservative management of vestibular schwannoma. Study design: Observational study.

Setting: Tertiary referral centre.

Patients: Four hundred and thirty-six patients with vestibular schwannoma (490 tumours), including 327 sporadic tumours and 163 tumours in 109 patients with neurofibromatosis type two.

Main outcome measures: The relationship of tumour growth to tumour size at presentation, and to certain demographic features.

Results: The initial tumour size was significantly larger in the neurofibromatosis type two group (11 mm) than in the sporadic vestibular schwannoma group $(5.1 \mathrm{~mm})$. In both groups, 68 per cent of tumours did not grow during follow up (mean 3.6 years; range one to 14 years). The mean growth rate was $1.1 \mathrm{~mm} /$ year (range 0-15 mm/year) for sporadic tumours and $1.7 \mathrm{~mm} /$ year (range $0-18 \mathrm{~mm} /$ year) for neurofibromatosis type two tumours. The tumour growth rate correlated positively with tumour size in the sporadic tumour group, and correlated negatively with age in the neurofibromatosis type two group.

Conclusion: Two-thirds of vestibular schwannomas did not grow. Radiological surveillance is an acceptable approach in carefully selected patients. Once a sporadic vestibular schwannoma reaches $2 \mathrm{~cm}$ in intracranial diameter, it is likely to continue growing. We do not recommend conservative management for sporadic tumours with an intracranial diameter of $1.5 \mathrm{~cm}$ or more. Vestibular schwannoma management is more complex in patients with neurofibromatosis type two.
\end{abstract}

Key words: Neuroma, Acoustic; Magnetic Resonance Imaging; Neurofibromatosis 2; Follow-up Studies

\section{Introduction}

The management of vestibular schwannoma has evolved over time. Surgery was the popular choice in earlier days, due to late diagnosis and large tumour size at presentation. Non-surgical treatment was not entertained as an option. The advent of computed tomography and the more accurate modality of magnetic resonance imaging (MRI) enabled a new management approach of 'wait and rescan', because of these imaging modalities' ability to detect smaller tumours. The majority of vestibular schwannomas may never grow, within the patient's lifespan, to a size requiring treatment, a fact supported by cadaveric studies showing a vestibular schwannoma incidence of $0.6-0.9$ per cent. Stereotactic radiosurgery has enabled a third management option for growing tumours, depending on the patient's wishes and general fitness and the tumour size. Nevertheless, surgery continues to play a crucial role in the treatment of patients with larger or growing tumours.

Over time, the clinician's perspective has changed, and the treatment goal has shifted from complete tumour removal to preservation of hearing and facial nerve function.

Now, if patients' schwannomas are diagnosed sufficiently early, all three management options can be offered. In order to counsel correctly patients with small tumours, the clinician must select the best management in each case. It would be ideal if clinicians could predict which tumours will grow and which will not. A better understanding of the growth pattern of vestibular schwannomas would assist such decisionmaking. If the growth rate could be predicted preoperatively, this may improve selection of surgical candidates. Several studies have addressed this issue.

We wish to add to this enquiry information on vestibular schwannoma behaviour derived from our own patient series.

\section{Materials and methods}

Study design

This study was based mainly on data collected and maintained by the senior author (RTR). From this

From the Departments of Otolaryngology, $\dagger$ Neurosurgery, $\ddagger$ Medical Genetics and **Neuroradiology, Manchester Royal Infirmary and Hope Hospital, Salford, and the *Department of Otology - Neuro-otology, University College London Ear Institute, Royal National Throat, Nose and Ear Hospital, London, UK.

Accepted for publication: 14 September 2009. First published online 11 December 2009. 
data, the following details were extracted: patient age and sex; initial tumour size; change in tumour size at follow up; reasons for conservative management; and outcome. We analysed separately sporadic vestibular schwannomas and those occurring as part of neurofibromatosis type two (NF2).

\section{Inclusion criteria}

We included in the study patients with vestibular schwannoma who were initially managed by radiological surveillance using serial (usually annual) MRI scans.

\section{Exclusion criteria}

Patients were excluded if they had cerebellopontine angle tumours other than vestibular schwannoma, or if they had undergone previous surgery or radiation therapy. No sporadic vestibular schwannoma with an intracranial diameter greater than $2 \mathrm{~cm}$ was included in the study, as it was already our policy to recommend microsurgery or irradiation for such tumours. There was no such exclusion for NF2-associated vestibular schwannomas, as many of these patients had large, unoperated tumours which were managed conservatively in an attempt to preserve hearing for as long as possible.

\section{Outcome measures and variables}

The tumour size recorded was the maximum tumour dimension in the cerebellopontine angle (i.e. intracranial), calculated on the basis of measurements taken along the longest measurable distance on a single image. This could be either the longest anteroposterior or medio-lateral dimension. Patients with intracanalicular tumours were classified separately as the intrameatal group, and the size of these tumours was described as $0 \mathrm{~mm}$ intracranial. The tumour growth rate was calculated by noting the change in tumour size between the initial scan and the latest available scan and then dividing this figure by the interval between the scans. Tumour growth was defined as an increase in the maximum tumour dimension of more than $1 \mathrm{~mm}$ along the same axis on serial scans.

\section{Statistical analysis}

Statistical methods were used to evaluate separately the growth rate and the frequency of growth in sporadic and NF2 vestibular schwannomas. Pearson correlation was used to study the association between age, initial tumour size and growth rate. The MannWhitney test was used to compare the median values in different groups, as the data were non-parametric in distribution. The criterion for statistical significance was set at $p<0.05$. The Kaplan-Meier method was used to determine the probability of growth overall, and to compare subgroups. The Statistical Package for the Social Sciences version 16 software was used for statistical analysis.

\section{Results}

Over a period of 29 years up to 2006, more than 1600 vestibular schwannomas have been managed in the otolaryngology department of the Manchester Royal Infirmary, UK. Up until 1992, every patient referred with vestibular schwannoma underwent surgery. Thereafter, conservative management began to be adopted due to the advent of MRI, with its ability to detect very small tumours (Figure 1).

Over the study period, 490 vestibular schwannomas (in 436 patients) were selected for conservative radiological surveillance. Of these, 327 were sporadic tumours, whilst 163 tumours in 109 patients occurred as part of NF2 (54 patients had bilateral tumours). The follow-up period for these 'wait and rescan' patients varied from one to 14 years (mean 3.6 years; median 3.3 years). The mean age at presentation was significantly higher in the sporadic group than in the NF2 group (Table I). There was a slight male preponderance in the sporadic group (1.17:1), while the sex incidence was nearly equal in the NF2 group (1.03:1).

The mean and median initial tumour sizes (Table I) were significantly larger in the NF2 group compared with the sporadic group. The statistical significance of the difference between the two medians

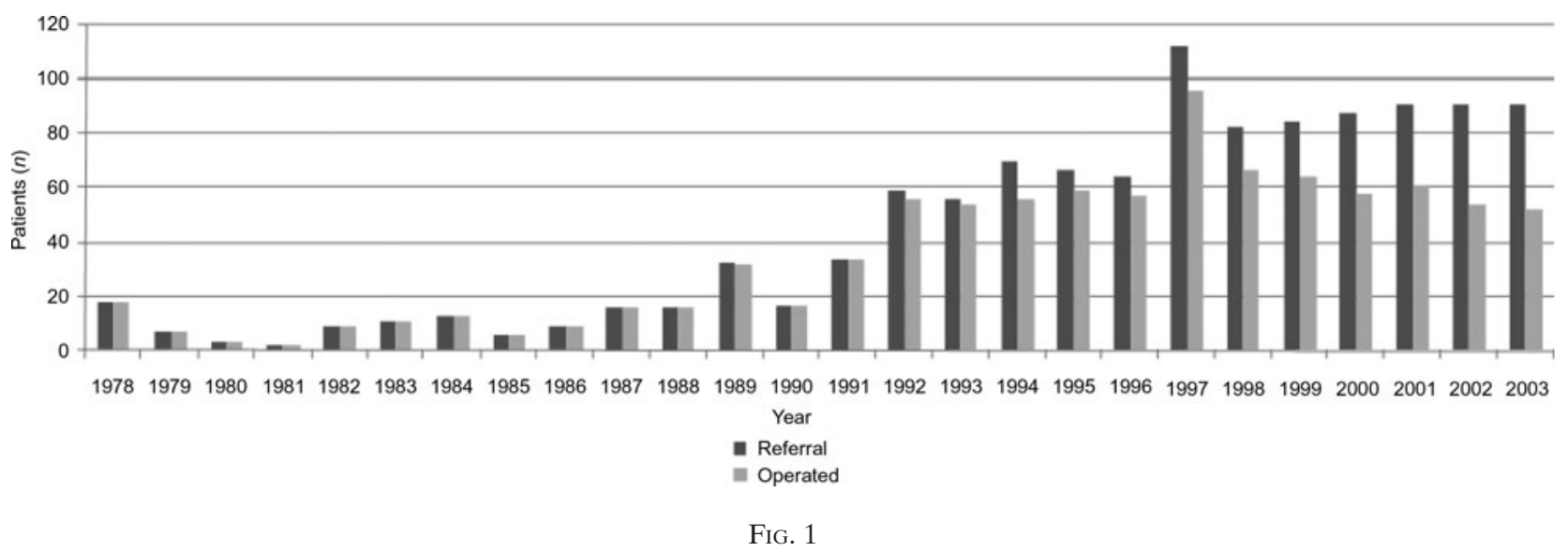

Patients with vestibular schwannoma referred to and operated upon in our department, indicating the change in management policy that occurred in 1992 (data available from 1978 to 2003). 
TABLE I

PATIENT DEMOGRAPHICS AND INITIAL VESTIBULAR SCHWANNOMA SIZE

\begin{tabular}{lll}
\hline Parameter & \multicolumn{2}{c}{ VS type } \\
\cline { 2 - 3 } & Sporadic & NF2 \\
\hline Sex ratio* & $176: 151$ & $56: 54$ \\
Mean age (y) & 60.5 & 30.8 \\
Age range (y) & $20-85$ & $7-70$ \\
Initial tumour size (mm) & & \\
Mean & 5.1 & 11 \\
Median & 2.5 & 8.8 \\
Range & IC to 20 & IC to 40 \\
\hline
\end{tabular}

*Male:female. VS = vestibular schwannoma; NF2 = neurofibromatosis type two; $\mathrm{y}=$ years; $\mathrm{IC}=$ intracanalicular

was $p=0.001$ (Mann-Whitney U test). Forty-seven per cent of the sporadic tumours and 31 per cent of the NF2 tumours were intracanalicular at presentation. Patient age correlated negatively with initial tumour size in the NF2 group (Pearson correlation coefficient $=-0.220 ; p=0.028)$. There was no significant correlation between patient age and tumour size in the sporadic group. The tumours were graded based on their initial size (Table II).

Reasons for pursuing a 'watch and rescan' management policy for sporadic tumours are given in Table III. They included small tumour size, absence of demonstrable growth, long duration of symptoms, tumour involving the better hearing ear or only hearing ear (e.g. in patients who had had a vestibular schwannoma removed from the opposite ear), poor medical history, and patient preference. In many cases, two or more factors influenced the decision.

Of the 327 patients with sporadic tumours, 41 were still awaiting their second scan at the time of analysis and were thus excluded. Of the remaining 286 patients, 72 proceeded to treatment after a period of watching (60 underwent microsurgery and 12 stereotactic radiosurgery). The commonest reason to proceed to treatment was tumour growth, but three patients preferred treatment even in the absence of growth. Five patients were discharged (two refused further scanning, two were in poor health and one wished to be discharged). Eight patients died of unrelated causes after a period of

TABLE II

VESTIBULAR SCHWANNOMA GRADING BY INITIAL SIZE* ${ }^{1}$

\begin{tabular}{lcc}
\hline Grade & \multicolumn{2}{c}{ VS type } \\
\cline { 2 - 3 } & Non-NF2 & NF2 \\
\hline Intrameatal & 155 & 50 \\
Grade 1 (1-10 mm IC) & 132 & 54 \\
Grade 2 (11-20 mm IC) & 34 & 28 \\
Grade 3 (21-30 mm IC) & 0 & 11 \\
Grade 4 (31-40 mm IC) & 0 & 7 \\
Grade 5 (>40 mm IC) & 0 & 4 \\
\hline
\end{tabular}

All data represent tumour numbers. ${ }^{*}$ Maximum tumour dimension. $\mathrm{VS}=$ vestibular schwannoma; $\mathrm{NF} 2=$ neurofibromatosis type two; $\mathrm{IC}=$ intracranial
TABLE III

REASONS FOR CONSERVATIVE MANAGEMENT OF THE SPORADIC TUMOURS

\begin{tabular}{lc}
\hline Reason & Tumours (\%) \\
\hline Small size & 22 \\
No growth & 14 \\
Long history & 12 \\
Better or only hearing ear & 29 \\
Patient preference & 5 \\
Co-morbidity & 18 \\
Minimal symptoms & 5 \\
\hline
\end{tabular}

watchful waiting. Nine patients were lost to follow up. Follow-up records were unavailable for 11 patients. At the end of the study, 63 per cent of patients with sporadic tumours (181 of 286) continued to remain under watchful waiting.

Of the 109 patients (163 tumours) in the NF2 group, five (seven tumours) were awaiting a second scan at the time of analysis and were thus excluded. Of the remaining 156 tumours, 45 were treated by surgery and six by stereotactic radiotherapy. Four patients (seven tumours) were lost to follow up. One patient (two tumours) received treatment elsewhere. Follow-up records were unavailable for seven patients (10 tumours). At the end of the study, 55 per cent of the NF2 tumours (86 of 156) continued to remain under radiological surveillance.

Data on growth were available for 240 sporadic tumours and 115 NF2 tumours (Table IV). The majority of the tumours in both groups (68 per cent) showed no change in tumour size over the period of observation. However, nearly one-third of the tumours in each group did demonstrate growth during the follow-up period. All growing tumours were identified within the first four years of follow up. The initial size of the growing tumours ranged from $0 \mathrm{~mm}$ (intracanalicular) to $20 \mathrm{~mm}$ in the sporadic group and from $0 \mathrm{~mm}$ (intracanalicular) to $50 \mathrm{~mm}$ in the NF2 group. The initial tumour size of the static tumours varied from $0 \mathrm{~mm}$ (intracanalicular) to $20 \mathrm{~mm}$ in the sporadic group and from $0 \mathrm{~mm}$ (intracanalicular) to $40 \mathrm{~mm}$ in the NF2 group. In both the sporadic and NF2 groups, growing tumours had a significantly larger initial size compared with static tumours (Table V). Figures 2 and 3 show the proportion of growing tumours compared with initial tumour size, for both groups. The proportion of growing tumours tended to increase with tumour grade in both groups. Kaplan-Meier survival

TABLE IV

VESTIBULAR SCHWANNOMA GROWTH PATTERNS

\begin{tabular}{lcc}
\hline Pattern & \multicolumn{2}{c}{ VS type $(n(\%))$} \\
\cline { 2 - 3 } & Sporadic & NF2 \\
\hline Growth & $74 / 240(30)$ & $37 / 115(32)$ \\
No change & $162 / 240(68)$ & $78 / 115(68)$ \\
Regression & $4 / 240(2)$ & 0 \\
\hline
\end{tabular}

$\mathrm{VS}=$ vestibular schwannoma; $\mathrm{NF} 2=$ neurofibromatosis type two 
TABLE V

INITIAL SIZE* OF GROWING AND STATIC VESTIBULAR SCHWANNOMAS

\begin{tabular}{llll}
\hline Size $(\mathrm{mm})$ & \multicolumn{2}{c}{ VS type } & $p^{\dagger}$ \\
\cline { 2 - 3 } & Growing & \multicolumn{1}{c}{ Static } & \\
\hline $\begin{array}{l}\text { Sporadic } \\
\text { Mean (range) }\end{array}$ & $6.8(0-20)$ & $4.6(0-20)$ & \\
$\begin{array}{l}\text { Median } \\
\text { NF2 }\end{array}$ & 5 & 0 & 0.0123 \\
Mean (range) & $15.4(0-50)$ & $7.4(0-40)$ & \\
Median & 15 & 5 & 0.0001 \\
\hline
\end{tabular}

A value of $0 \mathrm{~mm}$ was given to intrameatal (intracanalicular) tumours for statistical calculations. *Maximum tumour dimension. ${ }^{\dagger}$ Mann-Whitney test. VS = vestibular schwannoma; $\mathrm{NF} 2$ = neurofibromatosis type two

analysis showed that the probability of tumour growth was significantly higher for tumours with an extracanalicular size of more than $15 \mathrm{~mm}$ (both sporadic and NF2) (Figures 4 and 5). KaplanMeier analysis also showed a higher probability of growth for extracanalicular sporadic tumours than intracanalicular ones (Figure 6). Four sporadic tumours regressed in size; of these, one tumour had an initial size of $5 \mathrm{~mm}$ and the remainder were intrameatal.

The mean tumour growth rate was higher in the NF2 group compared with the sporadic group, but this difference was not statistically significant (Table VI). However, the growth rate was significantly higher in tumours that required intervention than in those that did not (Table VII). In the sporadic group, the tumour growth rate correlated positively with the initial tumour size (Pearson correlation coefficient $=$ $0.334 ; p=0.00$ ). However, there was no such correlation in the NF2 group. The growth rate correlated negatively with patient age in the NF2 group (Pearson correlation coefficient $=-0.287 ; p=0.014$ ) No such correlation was found in the sporadic group. In both groups, there was no correlation between patient sex and tumour growth rate.

Twelve of the sporadic and six of the NF2 tumours had a cystic tumour. Their initial size varied from $0 \mathrm{~mm}$ (intracanalicular) to $20 \mathrm{~mm}$ in the sporadic

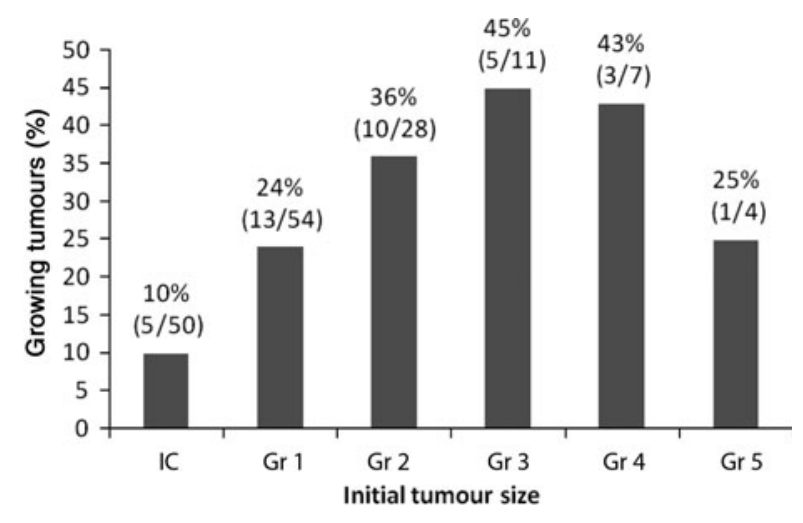

FIG. 2

Proportion of growing tumours versus initial size in neurofibromatosis type two vestibular schwannoma group. IC $=$ intracanalicular

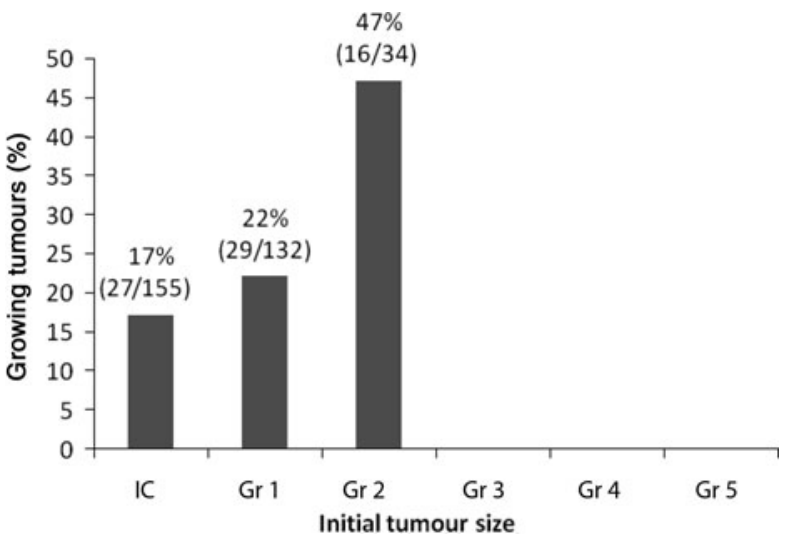

FIG. 3

Proportion of growing tumours versus initial size in sporadic vestibular schwannoma group. $\mathrm{IC}=$ intracanalicular.

group and $0 \mathrm{~mm}$ (intracanalicular) to $30 \mathrm{~mm}$ in the NF2 group. Five tumours grew at a rate of $5 \mathrm{~mm} /$ year.

Patients' overall mean pure tone average at presentation was $47 \mathrm{~dB}$, ranging from $0 \mathrm{~dB}$ to a 'dead ear'. Their speech discrimination scores varied from 0 to 100 per cent, with a mean of 55 per cent. The mean pure tone average and speech discrimination score were $52 \mathrm{~dB}$ and 48 per cent in the sporadic group and $37 \mathrm{~dB}$ and 72 per cent in the NF2 group, respectively. The initial tumour size did not correlate with either the pure tone average or the maximum speech discrimination score.

\section{Discussion}

Over the years, several attempts have been made to understand the natural behaviour of vestibular

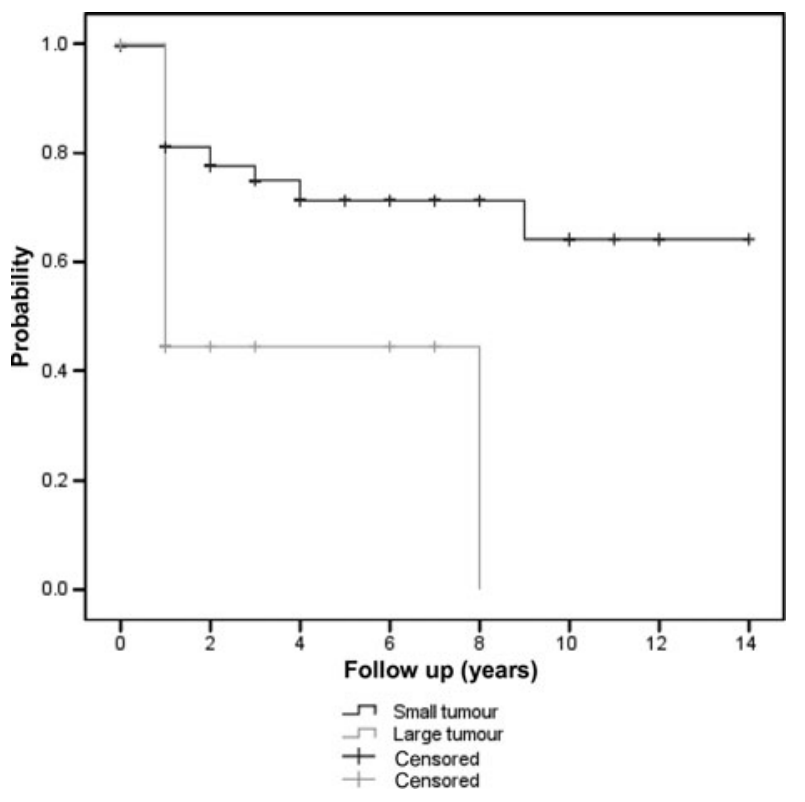

FIG. 4

Kaplan-Meier curves for growth probability of sporadic vestibular schwannomas with initial extracanalicular size $<15 \mathrm{~mm}$ versus $>15 \mathrm{~mm}$, showing significant difference in 'no growth rate' (log rank test: chi-square $=18.1 ; p=0.00)$. 


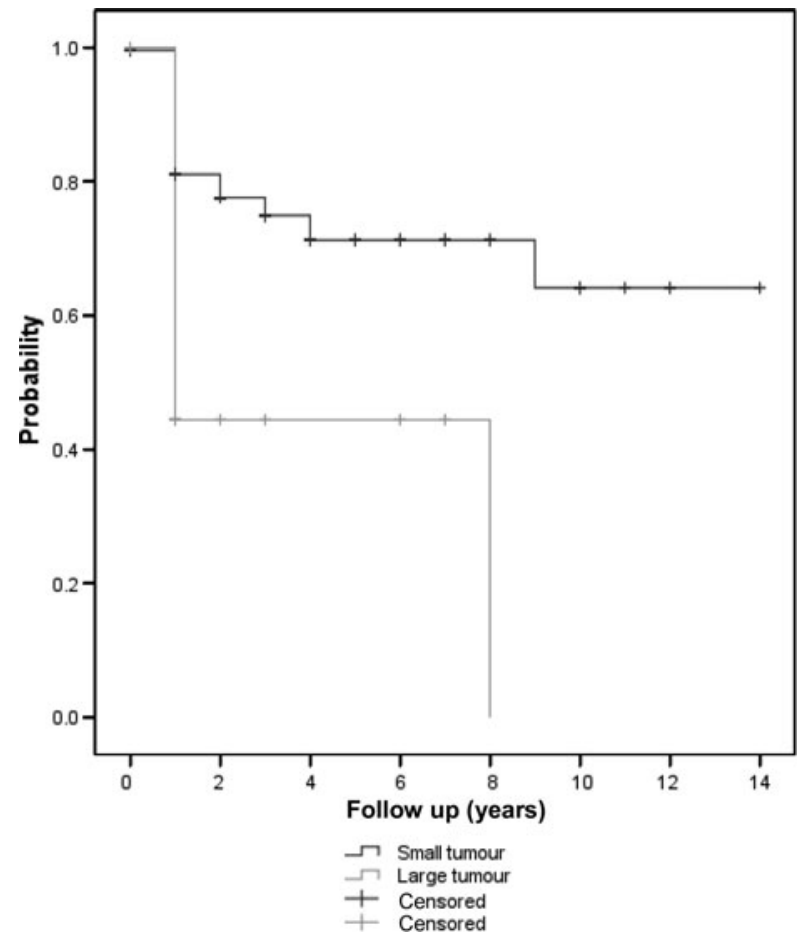

FIG. 5

Kaplan-Meier curves for growth probability of neurofibromatosis type two vestibular schwannomas with initial extracanalicular size $<15 \mathrm{~mm}$ versus $>15 \mathrm{~mm}$, showing significant difference in 'no growth rate' (log rank test: chi-square $=7.5 ; p=0.006$ ).

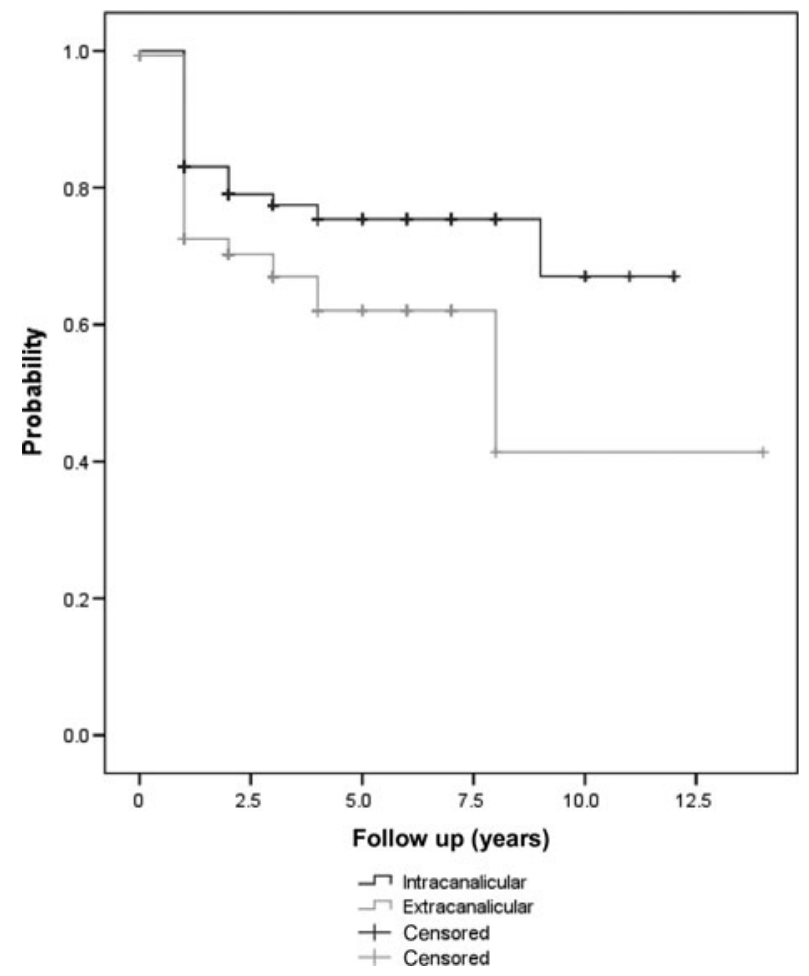

FIG. 6

Kaplan-Meier curves for intracanalicular versus extracanalicular sporadic vestibular schwannoma, showing significant difference in 'no growth rate' (log rank test: chi-square $=5.2 ; p=0.023$ ).
TABLE VI

VESTIBULAR SCHWANNOMA GROWTH RATES

\begin{tabular}{lccc}
\hline VS type & Mean & Median & Range \\
\hline Sporadic & 1.1 & 0 & $0-15$ \\
NF2 & 1.7 & 0 & $0-18$ \\
\hline
\end{tabular}

Data represent growth rates in $\mathrm{mm} /$ year. $\mathrm{VS}=$ vestibular schwannoma; NF2 = neurofibromatosis type two

TABLE VII

ANNUAL VESTIBULAR SCHWANNOMA GROWTH RATE: TREATED $V S$ WATCHED TUMOURS

\begin{tabular}{llll}
\hline Growth rate $(\mathrm{mm} / \mathrm{y})$ & Treated & Watched & $p^{*}$ \\
\hline Sporadic & & & \\
Mean & 4.8 & 0.18 & \\
Median & 3.4 & 0 & 0.00 \\
Range & $0-15$ & $0-4$ & \\
$N F 2$ & & & \\
Mean & 5.8 & 0.5 & 0.00 \\
Median & 5.0 & 0 & \\
Range & $0-18$ & $0-11$ & \\
\hline
\end{tabular}

*Mann-Whitney test. Y=year; NF2=neurofibromatosis type two

schwannomas. The ideal way to identify the effect of the various management modalities available (such as radiological surveillance, surgery and radiotherapy) would be to perform randomised, controlled trials, but in reality this is difficult. For that reason, the published literature contains no evidence better than level three or four. ${ }^{2}$ At present, it appears that the best available method of identifying the growth characteristics of this tumour is a prospective study using serial MRI scanning. ${ }^{3,4}$

Nearly two-thirds of our patients did not show any change in their vestibular schwannoma size over the study period. The reported proportion of growing tumours varies from 43 to 54 per cent (Table VIII). ${ }^{3,5-7}$ The mean annual growth rate identified by the studies shown in Table VIII varied from 1.2 to $1.9 \mathrm{~mm} /$ year; this is similar to our results for the overall annual growth rate of sporadic tumours (1.1 mm/year) as well as NF2 tumours (1.7 mm/year).

As one would expect, we found a higher vestibular schwannoma growth rate in the NF2 group than in the sporadic tumour group. Vestibular schwannoma growth rates in NF2 are highly variable and tend to decrease with increasing age. ${ }^{8}$ This may be due in part to the fact that patients with slower growing tumours are more likely to have a 'benign' phenotype and are thus more likely to live to old age. Although the decision to intervene is influenced by such factors as patient choice, presence of co-morbidity, hearing status and patient age, in our study tumour growth appeared to be the main deciding factor, as demonstrated by the significantly higher tumour growth rate in the treated group.

We found that the vestibular schwannoma growth rate correlated positively with the initial tumour size in the sporadic group, and correlated negatively with patient age in the NF2 group. We did not find 
TABLE VIII

PREVIOUS REVIEWS OF VESTIBULAR SCHWANNOMA BEHAVIOUR AND CONSERVATIVE MANAGEMENT

\begin{tabular}{|c|c|c|c|c|}
\hline Parameter & Selesnick \& Johnson ${ }^{5}$ & Yoshimoto $^{3}$ & Smouha et al. ${ }^{6}$ & Yamakami et al. ${ }^{7}$ \\
\hline Study type & Meta-analysis & Meta-analysis & Meta-analysis & Systematic review \\
\hline Studies included $(n)$ & 13 & 26 & 21 & 13 \\
\hline Patients $(n)$ & 571 & 1340 & 1345 & 903 \\
\hline Mean age (y) & 64 & 62 & 62 & 65 \\
\hline Mean follow up & $3 y$ & $38 \mathrm{mth}$ & $3.2 \mathrm{y}$ & $3.1 \mathrm{y}$ \\
\hline Mean tumour size (mm) & 11.8 & 11 & 11.8 & 10 \\
\hline Mean tumour growth $(\mathrm{mm} / \mathrm{y})$ & 1.8 & 1.2 & 1.9 & 1.87 \\
\hline Growing tumours (\%) & 54 & $46^{*}$ & 43 & 51 \\
\hline Watched tumours needing treatment (\%) & 26 & 18 & 20 & 20 \\
\hline NF2 inclusion & Included & Excluded & Included & Included \\
\hline
\end{tabular}

${ }^{*}$ Overall; prospective studies, $29 \%$. Y = years; $\mathrm{mth}=$ months; NF2 = neurofibromatosis type two

any correlation with patient sex or symptom duration. There is no consensus in the literature to assist the prediction of growth based on information available at presentation. Ogawa et al. . $^{9}$ found tumour growth to be related to several factors such as age, sex and tumour size. They found a higher tumour growth rate in younger patients and those with larger tumours. They also found that female patients had larger tumours at presentation, and that their tumours grew faster than those in male patients. Other authors have also observed this tendency for increased tumour growth in younger patients, but more so in men than women. ${ }^{10-12}$ In contrast, Valvassori and Guzman found no correlation between tumour growth rate and patient age or length of follow up. ${ }^{13}$

In our patients with sporadic vestibular schwannoma, the initial tumour size did not correlate with patient age, a finding also reported by Mirz et al. ${ }^{14}$ However we found that the initial tumour size correlated positively with the tumour growth rate. We demonstrated quite clearly that grade two tumours grew faster than grade one tumours. Fucci et al. described a similar finding: tumours initially larger than $20 \mathrm{~mm}$ were more likely to grow than smaller tumours. ${ }^{15}$ Further, Martin and colleagues' 'intention to treat' analysis showed that conservative management of vestibular schwannomas with an intracranial size of up to $20 \mathrm{~mm}$ was safe and yielded significantly better preservation of facial nerve function and hearing, compared with surgical management. ${ }^{16}$ Intracanalicular tumours do not exhibit significant growth, compared with tumours with extension into the cerebellopontine angle. ${ }^{17}$

We found a significantly higher probability of growth in vestibular schwannomas with an intracranial size of more than $15 \mathrm{~mm}$, in both the sporadic and NF2 groups. Our findings have subsequently influenced our management strategy for sporadic vestibular schwannomas. We now discuss active management with all patients with tumours of $15 \mathrm{~mm}$ intracranial diameter or more - usually microsurgery, or stereotactic radiosurgery in a minority. This is in close agreement with the large Copenhagen series of Charabi et al. ${ }^{18}$

These authors also found symptom duration to have predictive value in identifying tumour growth, but this has not been confirmed by our or any other study. Tschudi et al. showed that patients with progressive hearing loss as a first symptom had significantly slower tumour growth than those presenting with tinnitus, sudden hearing loss or dizziness. ${ }^{19}$ We found no correlation between tumour size at presentation and hearing level. Some authors have found positive growth during the first year of observation to be predictive of future growth. ${ }^{12,19-21}$

Previous studies involving the senior author's patients concluded that the clinical features evident at presentation and diagnosis have no power to predict the expected behaviour of sporadic vestibular schwannoma. ${ }^{22,23}$ These studies also showed that growth estimates based on clinical history have no predictive ability. Furthermore, sporadic vestibular schwannoma has been shown to exhibit many different growth patterns, such as: stability; initial growth followed by stability; stability followed by regression; stability followed by growth; continuous regression; and continuous growth. ${ }^{19,24}$ It appears that the only way to identify growing tumours is to follow them regularly with imaging.

- Conservative radiological surveillance is an acceptable method of managing vestibular schwannomas

- Growing tumours are identifiable within the first five years of follow up

- Treatment should be offered to patients with sporadic vestibular schwannomas with an intracranial size exceeding $15 \mathrm{~mm}$

- Decisions regarding management of neurofibromatosis type two vestibular schwannomas are more complex

Clinicians working in this field will be aware of just how problematic decision-making can be for patients suffering from NF2. Tumour behaviour varies enormously depending on the genotype and phenotype of the individual. ${ }^{25,26}$ Because of the bilateral nature of the disease, there is often reluctance on the part of the surgeon or the patient to consider removing a tumour if there is still useful hearing on that side, especially if the opposite ear is completely deaf. For that reason, we are often prepared to observe even grade four tumours until such time as 
hearing is lost naturally, or until removal becomes a neurosurgical imperative.

We acknowledge that the outcome of conservative management in our group of patients is in keeping with other published series and holds no surprises. However, the current study differs from several others in its methodology. Most of the data on growth were collected prospectively. In particular, every tumour size measurement was performed by the senior author (RTR) himself in the clinic, thereby reducing inter-observer variability. In order to maximise the identification of growing tumours, we considered a change in dimension of $1 \mathrm{~mm}$ to be significant, as opposed to many other published studies which used a value of $2 \mathrm{~mm}$ or more. We also followed the guidelines set out at the consensus meeting on reporting the results of vestibular schwannoma management, held in Tokyo in 2001. We hope that future authors will also report their results based on these guidelines, as this will assist future meta-analysis.

\section{Conclusion}

In this study, two-thirds of patients' vestibular schwannomas showed no growth. Conservative management, using serial scans, can be regarded as a safe approach in carefully selected patients with vestibular schwannoma. Factors that influence the decision to recommend surgery include patient choice, general health, hearing levels (in both the ipsilateral and contralateral ears) and whether the patient has NF2. The most important criterion, however, is the size of the tumour at presentation. Once a sporadic vestibular schwannoma reaches $15 \mathrm{~mm}$ (intracranial diameter), it is likely to continue growing. As a result of this study, we do not recommend conservative management for sporadic tumours with an intracranial diameter of $15 \mathrm{~mm}$ or more. There are different patterns of tumour growth in NF2; for patients with this condition, management decisions are more complex.

\section{References}

1 Kanzaki J, Tos M, Sanna M. New and modified reporting systems from the consensus meeting on systems for reporting results in Vestibular Schwannoma. Otol Neurotol 2003; 24:642-9

2 Nikolopoulos TP, O’Donoghue GM. Acoustic neuroma management: an evidence-based medicine approach. Otol Neurotol 2002;23:534-41

3 Yoshimoto Y. Systematic review of the natural history of vestibular schwannoma. J Neurosurg 2005;103:59-63

4 Suryanarayanan R, Lesser THJ. Growth rate of vestibular schwannoma - what the literature tells us. The Otorhinolaryngologist 2007;1:66-71

5 Selesnick HS, Johnson G. Radiologic surveillance of acoustic neuromas. Am J Otol 1998;19:846-9

6 Smouha EE, Yoo M, Mohr K, Davis RP. Conservative management of acoustic neuroma: a meta-analysis and proposed treatment algorithm. Laryngoscope 2005;115:450-4

7 Yamakami I, Uchino Y, Kobayashi E, Yamaura A. Conservative management, gamma-knife radiosurgery and microsurgery for acoustic neurinomas: a systematic review of outcome and risk of three therapeutic options. Neurol Res 2003;25:682-90

8 Baser ME, Mautner VF, Parry DM, Evans DGR. Methodological issues in longitudinal studies: vestibular schwannoma growth rates in neurofibromatosis 2. J Med Genet 2005;42:903-6

9 Ogawa K, Kanzaki J, Ogawa S, Yamamoto M, Ikeda S, Shiobara R. The growth rate of acoustic neuromas. Acta Otolaryngol Suppl 1991;487:157-63

10 Charabi S, Thomsen J, Tos M, Charabi B, Mantoni M, Borgesen SE. Acoustic neuroma/vestibular schwannoma growth: past, present and future. Acta Otolaryngol 1998;118:327-32

11 Niemczyk K, Vaneecloo FM, Lemaitre L, Lejeune JP, Skarzynski H, Dubrulle F. The growth of acoustic neuromas in volumetric radiologic assessment. Am J Otol 1999; 20:244-8

12 Laasonen E, Troupp H. Volume growth rate of acoustic neurinomas. Neuroradiology 1986;28:203-7

13 Valvassori GE, Guzman M. Growth rate of acoustic neuromas. Am J Otol 1989;10:174-6

14 Mirz F, Jorgensen B, Fiirgaard B, Lundorf E, Pedersen CB Investigations into the natural history of vestibular schwannomas. Clin Otol 1999;24:13-18

15 Fucci MJ, Buchman CA, Brackmann DE, Berliner KI. Acoustic tumour growth: implications for treatment choices. Am J Otol 1999;20:495-9

16 Martin TPC, Tzifa K, Kowalski C, Holder RL, Walsh R, Irving RM. Conservative versus primary surgical treatment of acoustic neuromas: a comparison of rates of facial nerve and hearing preservation. Clin Otolaryngol 2008;33:228-35

17 Walsh RM, Bath AP, Bance ML, Keller A, Tator CH, Rutka JA. The role of conservative management of vestibular schwannomas. Clin Otolaryngol 2000;25:28-39

18 Charabi S, Thomsen J, Mantoni M, Charabi B, Jorgensen $\mathrm{B}$, Borgesen SE. Acoustic neuroma: growth and surgical and nonsurgical consequences of the wait and see policy. Otolaryngol Head Neck Surg 1995;113:5-14

19 Tschudi DC, Linder TE, Fisch U. Conservative management of unilateral acoustic neuromas. Am J Otol 2000;21:722-8

20 Deen HG, Ebersold MJ, Harner SG, Beatty CW, Marion MS, Wharen RE. Conservative management of acoustic neuroma: an outcome study. Neurosurgery 1996; 39:260-4

21 O'Reilly B, Murray CD, Hadley DM. The conservative management of acoustic neuroma: a review of forty-four patients with magnetic resonance imaging. Clin Otolaryngol 2000;25:93-7

22 Herwadker A, Vokurka EA, Evans DGR, Ramsden RT, Jackson A. Size and growth rate of sporadic vestibular schwannoma: predictive value of information available at presentation. Otol Neurotol 2005;26:86-92

23 Mohyuddin A, Vokurka EA, Evans DG, Ramsden RT, Jackson A. Is clinical growth index a reliable predictor of tumor growth in vestibular schwannomas? Clin Otolaryngol 2003;28:85-90

24 Rosenberg SI. Natural history of acoustic neuromas. Laryngoscope 2000;110:497-508

25 Evans DG, Trueman L, Wallace A, Collins S, Strachan T. Genotype/phenotype correlations in type 2 neurofibromatosis (NF2): evidence for more severe disease associated with truncating mutations. $J$ Med Genet 1998;35:450-5

26 Baser ME, Kuramoto L, Joe H, Friedman JM, Wallace AJ, Gillespie JE et al. Genotype-phenotype correlations for nervous system tumors in neurofibromatosis 2: a populationbased study. Am J Hum Genet 2004;75:231-9

Address for correspondence:

Mr R Suryanarayanan,

56 California Close,

Warrington WA5 8WU, UK.

Fax: 01925415280

E-mail: drsury@gmail.com

Mr R Suryanarayanan takes responsibility for the integrity of the content of the paper.

Competing interests: None declared 